\title{
MAKALAH BOLA VOLI
}

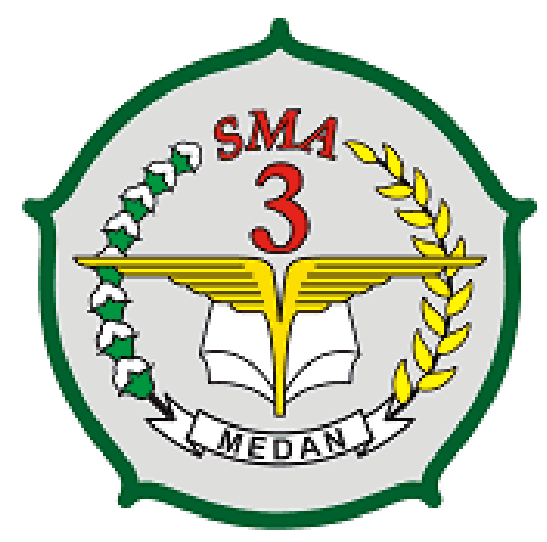

NAMA: AZRAH KAMILA KELAS: X- MIA- 6 


\section{KATA PENGANTAR}

Puji syukur kehadirat Tuhan Yang Maha Esa yang telah memberi taufik, hidayah, serta inayahNya sehingga kita semua masih bisa beraktivitas sebagaimana seperti biasanya termasuk juga dengan penulis, sehingga penulis dapat menyelesaikan tugas pembuatan makalah yang berjudul "Bola Voli". Dalam makalah ini, penulis membahas tentang sejarah perkembangan olahraga Bola Voli, pengertian olahraga Bola Voli, tehnik yang digunakan dalam olahraga Bola Voli, serta masih banyak pembahasan lainya yang disajikan dalam bentuk makalah. Makalah ini disusun agar para pembaca bisa menambah wawasan serta memperluas ilmu pengetahuan yang ada mengenai Bola Voli.

Penulis menyadari bahwa masih banyak kekurangan yang mendasar pada makalah ini. Oleh karena itu penyusun mengundang pembaca untuk memberikan saran serta kritik yang dapat membangun untuk dapat memperbaiki tugas makalah selanjutnya. Dan semoga makalah ini bisa bermanfaat untuk para pembaca dan memperluas wawasan mengenai Bola Voli serta seluk beluknya. Dan tidak lupa permohonan maaf dari penulis apabila terdapat kekurangan dan kesalahan dalam bentuk apapun yang terdapat dalam makalah ini. 


\section{PENDAHULUAN}

\section{A, Latar Belakang}

Pemainan bola voli merupakan pemainan beregu yang dimainkan oleh dua regu dengan jumlah pemain masing - masing regu enam orang. Dimainkan dengan cara memvoli bola hilir mudik diatas net dan masing - masing regu berusaha secepat nya menjatuhkan bola di lapangan lawan dengan pantulan bola sempurna. Penguasaan teknik, kemampuan fisik, taktik, dan mental yang baik, serta kerja sama sangat di butuhkan untuk memenangkan permainan .

Permainan bola voli diciptakan oleh William G. Morgan pada tahun 1895. Beliau adalah seorang pembina pendidikan jasmani pada organisasi Young Men's Christian Association (YMCA) di kota Massachusetts, Amerika Serikat. Pada mulanya, pemainan bola voli di beri nama mintonete, di mana tujuan semula, yaitu untuk mengembangkan kesegaran jasmani pada tubuh, selain untuk bersenam umum.

Kemudian, permainan ini di ubah menjadi volleyball yang artinya memvoli bola secara bergantian. Tahun 1892, YMCA berhasil mengadakan kejuaraan nasional bola voli di Amerika Serikat. Pada tahun 1847, untuk pertama kalinya permainan bola voli dipertandingkan di Polandia. Pada tahun 1948 dibentuk organisasi bola voli dunia dengan nama IVBF (International Volley Ball Federation ) dengan beranggota 15 negara dan berpusat di Paris.

\section{B. Rumusan Masalah}

1. Sejarah Permainan Bola Voli

2. Pengertian bola voli

3. Teknik Dasar Permainan Bola Voli

4. Prasarana Permainan Bola Voli

5. Bagaimana peraturan dalam olahraga Bola Voli

6. Strategi permainan bola voli

\section{Tujuan}

1. Mengetahui sejarah bola voli

2. Mengetahui penegrtian bola voli

3. Mengetahui teknik dasar permainan bola voli

4. Mengetahui prasarana permainan bola voli

5. Mengetahui peraturan dalam olahraga bola voli

6. Mengetahui strategi permainan bola voli 


\section{PEMBAHASAN}

\section{A. Sejarah Permainan Bola Voli}

Permainan bola voli diciptakan oleh William B Morgan pada tahun 1895 di Holyoke (Amerika bagian timur). William B Morgan adalah seorang pembina pendidikan jasmani pada Young Men Christain Association (MCA). Permainan bola voli diciptakan oleh William B Morgan pada tahun 1895 di Holyoke (Amerika bagian timur). William B Morgan adalah seorang pembina pendidikan jasmani pada Young Men Christain Association (MCA). Kemudian permainan bola

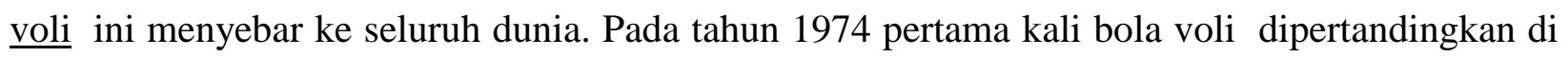
Polandia dengan peserta yang cukup banyak. Maka pada tahun 1984 didirikan Federasi Bola Voli Internasional atau Internationnal Voli Ball Federation (IVBF) yang waktu itu beranggotakan 15 negara dan berkedudukan di Paris.

Permainan bola voli sangat cepat perkembangannya, antar lain disebabkan oleh :

1. Tidak memerlukan lapangan yang luas.

2. Mudah dimainkan.

3. Alat-alat yang digunakan untuk bermain sangat sederhana.

4. Permainan ini sangat menyenangkan.

5. Kemungkinan terjadinya kecelakaan sangat kecil.

6. Dapat dimainkan di alam bebas maupun di ruang tertutup.

7. Dapat di mainkan banyak orang

\section{B. Pengertian Bola Voli}

Permainan bola voli masuk ke Indonesia pada waktu penjajahan Belanda (sesudah tahun 1928). Perkembangan permainan bola voli di Indodesia sangat cepat. Hal ini terbukti pada Pekan Olahraga Nasional (PON) ke-2 tahun 1952 di jakarta. Sampai sekarang permainanbola voli termasuk salah satu cabang olahraga yang resmi dipertandingkan. Pada tahun 1955 tepatnya tanggal 22 Januari didirikan Organisasi Bola Voli Seluruh Indonesia (PBVSI) dengan ketuanya W. J. Latumenten. Setelah adanya induk organisasi bola voli ini, maka pada tanggal 28 sampai 30 mei 1955 diadakan kongres dan kejuaraan nasional yang pertama di Jakarta. Dengan melihat perkembangan permainan bola voli yang begitu pesat sangatlah tepat bila pemerintah memilih permainan bola voli sebagai olahraga pendidikan di sekolah-sekolah. Hanya pada umumnya permainan bola voli sedikit mengalami kesulitan di dalam memperkenalkan pada anak-anak didik. Kesulitan ini terletak pada gerakan dasar permainan bola voli . 


\section{Teknik Dasar Bola Voli}

\section{Pengertian Teknik}

Teknik adalah suatu proses melahirkan keaktifan jasmani dan pembuktian suatu peraktek dengan sebaik mungkin untuk menyelesaikan tugas yang pasti dalam cabang olahraga (khususnya cabang permainan bola voli ). Teknik dikatakan baik apabila dari segi anatomis/fisiologis mekanik dan mental terpenuhi secara benar persyaratannya. Apabila diterapkan pencapaian prestasi maksimal untuk menganalisa gerakan teknik, umumnya para guru atau pelatih akan dapat mengoreksi dan memperbaiki.

\section{Kegunaan Teknik Pada Cabang Olahraga}

- Efisien dan Efektif untuk mencapai prestasi maksimal.

- Untuk mencegah dan mengurangi terjadinya cidera

- Untuk menambah macam-macam teknik atlet ada saat pertandingan.

- Atlet akan lebih mantap dan optimis dalam memasuki arena pertandingan.

\section{Teknik Penguasaan Bola}

Untuk dapat menguasai bola secara maksimal dan sempurna seorang pemain setidaknya harus memiliki kemampuan-kemampuan seperti mampu melakukan passing atas secara baik dan benar dari teknik dasar ini tidak diabaikan dan harus dilatih dengn baik, seseorang harus mengerti dan benar-benar dapat menguasai teknik penguasaan bola dengan baik dan terus menerus.

\section{Passing Bawah}

Passing bawah biasanya dipergunakan oleh para pemain jika bola datangnya rendah, baik untuk dioperkan kepada teman seregunya maupun untuk dikembalikan ke lapangan lawan melewati atas jaring atau net.

\section{Passing Atas}

Passing atas atau passing tangan atas adalah cara pengambilan bola atau mengoper dari atas kepala dengan jari-jari tangan. Bola yang datang dari atas diambil dengan jari-jari tangan di atas, agak di depan kepala.

\section{Servis Bawah}

Servis bawah adalah cara melakukan pukulan permukaan dari petak service dengan memukul bola dengan tangan dari bawah sebagai usaha menghidupkan bola dalam permainan. Service bawah merupakan service yang dilakukan dengan tangan bawah, siku diluruskan dan 
ayunan tangan dari belakang ke depan melalui samping badan, salah satunya tangan memegang bola dan bola tersebut dilambungkan baru dipukul. Service ini sangat populer dan sering dilakukan oleh pemain pemula.

\section{Servis Atas}

Servis atas adalah cara melakukan pukulan permulaan dari bawah service dengan memukul bola dari atas kepala sebagai usaha menghidupkan bola ke dalam permainan (Aip Syarifuddi). Servise atas banyak variasinya, bola dapat dilambungkan dengan satu tangan atau dua tangan, tinggi lambungan bola tergantung dari maksud pukulan dan kesenangan pribadi pemain. Namun pada prinsipnya harus diusahakan agar bola dilambungkan sedemikian rupa tingginya, sehingga seluruh rangkaian gerakan memukul menjadi satu gerakan yang tidak terputus-putus.

\section{Servis Samping}

Servis samping adalah melakukan pukulan permulaan dari daerah service dengan sikap berdiri menyamping dan berat badan berada di kaki kanan (bagi yang tidak kidal), telapak tangan menghadap ke atas (Mariyanto, 1995 : 119). Adapun pelaksanaan service samping adalah service berdiri menyamping dengan tubuh bagian kiri lebih dekat dengan jaring (bagi yang tidak kidal) kedua tanga bersama-sama memegang bola. Pada saat bola akan dilambungkan, maka badan diliukkan ke belakang dan lutut ditekuk. Kedua tangan dijulurkan ke samping kanan, begitu bola lepas dari tangan, maka tangan ditarik kesamping kanan bawah, berat badan berada di kaki kanan, telapak tangan menghadap ke atas, pukulan tangan pada bola dibantu dengan liukan badan, lecutan lengan dan gerakan pergelangn tangan sehingga bola setelah dipukul melambung dengan keras dan topspin.

\section{Servis Lompat}

Servis lompat adalah cara melakukan pukulan permulaan di daerah service dengan melompat setelah bola dilambungkan dengan satu tangan atau dua tangan (Aip Syarifuddin, 1997 : 59). Service lompat dilakukan dengan bola dilambungkan dengan satu atau dua tangan. Begitu bola dilambungkan diikuti dengan melompat dan diusahakan bola berada di atas depan kepala. Bila bola telah berada di atas depan kepala maka segeralah tangan kanan dipukulkan pada bola secepatnya.

\section{Smash (Spike)}

Smesh atau spike adalah gerakan memukul bola yang dilakukan dengan kuat dan keras serta jalannya bola cepat, tajam dan menukik serta sulit diterima lawan apabila pukulan itu dilakukan dengan cepat dan tepat (Aip Syarifuddin, 1997 : 58). Pada teknik smash inilah letak seninya

permainan bola voli , apabila pemain hendak memenangkan pertandingan maka mau tidak mau mereka harus menguasai teknik smash. Pemain yang pandai melakukan smash atau dengan 
istilah smasher harus memiliki kelincahan, daya ledak, timing yang tepat dan mempunyai kemampuan memukul bola yang sempurna. Pemain bola voli akan dapat melakukan berbagai variasi smash apabila pemain tersebut menguasai teknik dasar smash secara baik dan benar.

\section{Membendung (Bloking)}

Membendung (Bloking) adalah bentuk gerakan seseorang atau beberapa orang pemain yang berada didekat net/pemain depan (Aip Syarifuddin, 1997 : 58). Tujuan untuk menutupi atau membendung datangnya bola dari lapangan lawan, caranya dengan menjulurkan kedua tangan ke atas dengan ketinggian yang kanan lebih tinggi dari tepian atau bibir net.

\section{Prasarana Permainan Bola Voli}

\section{Lapangan dan Ukurannya}

Lapangan permainan bola voli berbentuk persegi panjang dengan ukuran panjang $18 \mathrm{~m}$ dan lebar $9 \mathrm{~m}$, semua garis batas lapangan, garis tengah, garis daerah serang adalah $3 \mathrm{~m}$ (daerah depan). Garis batas itu diberi tanda batas dengan menggunakan tali, kayu, cat/kapur, kertas yang lebarnya tidak lebih dari $5 \mathrm{~cm}$. lapangan permainan bola voli terbagi menjadi dua bagian sama besar yang masing-masing luasnya 9 x 9 meter. Di tengah lapangan dibatasi garis tengah yang membagi lapangan menjadi dua bagian sama besar. Masing-masing lapangan terdiri dari atas daerah serang dan daerah pertahanan.

\section{Daerah Servis}

Daerah service adalah daerah selebar 9 meter di belakang setiap garis akhir. Daerah ini dibatasi oleh dua garis pendek sepanjang $15 \mathrm{~cm}$ yang dibuat $20 \mathrm{~cm}$ di belakang garis akhir, sebagai kepanjangan dari garis samping. Kedua garis pendek tersebut sudah termasuk di dalam batas daerah service, perpanjangan daerah service adalah kebelakang sampai batas akhir daerah bebas.

\section{Jaring (Net)}

Jaring untuk permainan bola voli berukuran tidak lebih dari 9,50 meter dan lebar tidak lebih dari 1,00 meter dengan petak-petak atau mata jaring berukuran $10 \times 10 \mathrm{~cm}$, tinggi net untuk putra 2,43 meter dan untuk putri 2,24 meter, tepian atas terdapat pita putih selebar $5 \mathrm{~cm}$.

\section{Antene Rod}

Di dalam pertandingan permainan $\underline{\text { bola voli }}$ yang sifatnya nasional maupun internasional, di atas batas samping jaring dipasang tongkat atau rod yang menonjol ke atas setinggi $80 \mathrm{~cm}$ dari tepi jaring atau bibir net. Tongkat itu terbuat dari bahan fibergelas dengan ukuran panjang $180 \mathrm{~cm}$ dengan diberi warna kontras. 


\section{Bola}

Bola harus bulat terbuat dari kulit yang lentur atau terbuat dari kulit sintetis yang bagian dalamnya dari karet atau bahan yang sejenis. Warna bola harus satu warna atau kombinasi dari beberapa warna. Bahan kulit sintetis dan kombinasi warna pada bola dipergunakan pada pertandingan resmi internasional harus sesuai dengan standar FIVB. Keliling bola $64-67 \mathrm{~cm}$ dan beratnya 260 - 280 grm, tekanan didalam bola harus 0, $39-0,325 \mathrm{~kg} / \mathrm{cm} 2 \quad(4,26-4,61$ Psi) (294,3 - 318,82 mbar/hpa).

\section{Pemain}

Jumlah pemain dalam lapangan permainan sebanyak 6 orang setiap regu dan ditambah 5 orang sebagai pemain cadangan dan satu orang pemain libero. Satu tim maksimal terdiri dari 12 pemain, saru coach, satu sistem coach, satu trainer, dan satu dokter medis, kecuali libero, satu dari para pemain adalah kapten tim, dia harus diberi tanda dalam score sheet. Hanya pemain terdaftar dalam score sheet dapat memasuki lapangan dan bermain dalam pertandingan. Pada saat coach dan kapten tim menandatangani scoresheet pemain yang terdaftar tidak dapat diganti.

\section{E. Peraturan Permainan Bola Voli}

Setiap tim terdiri dari 6 pemain aktif atau berada didalam lapangan dan 4 pemain cadangan berada dibangku cadangan. Untuk memulai jalanya pertandingan denagan cara service terlebih dahulu oleh salah satu tim dan bola harus melewati net, jika gagal maka lawan mendapatkan poin. Apabila satu tim berhasil menjatuhkan bola ke daerah lawan maka tim tersebut mendapatkan poin.

\section{F. Strategi Permainan Bola Voli}

\section{$\underline{\text { Setter }}$}

Setter adalah pemain yang dispesialisasikan untuk mengatur bentuk penyerangan. Bola kedua setelah pass akan di set oleh setter, kemudian ia akan menempatkan bola di udara agar dapat di spike oleh attacker. Dengan demikian, setter dan attacker harus mampu menciptakan kerjasama dengan baik. Setter harus memiliki kualitas yang bagus dalam menyesuaikan arah dan tinggi bola yang akan di spike. Selain itu, setter haruslah seorang pemain yang lincah dan mampu bergerak dengan cepat di area permainan.

\section{$\underline{\text { Libero }}$}

Jika kita memperhatikan sebuah pertandingan bola voli, maka pada setiap tim kita akan melihat seorang pemain yang menggunakan seragam yang berbeda dengan semua pemain di timnya. Pemain dengan seragam yang berbeda itulah yang disebut dengan libero.Dalam bahasa Italia, 
libero mempunyai arti "bebas". Sesuai dengan nama tersebut, maka libero adalah pemain yang dapat secara bebas mengambil alih peran pemain yang lain. Namun, dalam sebuah pertandingan, libero tidak boleh memiliki dua posisi atau berganti posisi. Pada dasarnya, libero bertugas untuk menerima serangan-serangan (spikes) yang dilakukan oleh attacker tim lawan. Berdasarkan fungsi utama tersebut, maka seorang libero tidak harus memiliki postur tubuh yang tinggi seperti pemain yang lain. Hal ini karena seorang libero tidak bermain di area yang dekat dengan net. Yang paling ditekankan bagi seorang libero adalah kualitas pass yang baik, memiliki kecepatan gerak yang tinggi, dan tentu saja harus memiliki stamina yang baik.

\section{Blocker tengah (Middle Bolcker) atau spiker tengah (Middle Hitter)}

Middle blocker adalah pemain yang pada dasarnya bertugas menahan serangan attacker dari tim lawan. Namun, Middle blocker ini juga dapat bertugas sebagai seorang spiker. Biasanya, Middle blocker ini melakukan spike berupa quick hit.

\section{Spiker luar (Outside hitter)}

Outside hitter adalah seorang attacker yang melakukan spike dari sisi kiri lapangan. Disebut "Outside hitter", karena ketika hendak melakukan spike, pemain ini biasanya selalu mengambil awalan dari luar garis samping lapangan.

\section{$\underline{\text { Spiker Kanan (Right Side Hitter) }}$}

Right spike hitter adalah lawan dari Outside hitter. Pemain ini menempati posisi yang berlawanan dengan Outside hitter, yaitu di sebelah kanan. Spike-pun dilakukan dari sebelah kanan. Biasanya, Right side hitter adalah salah seorang pemain yang paling banyak melakukan spike dalam sebuah pertandingan bola voli dibandingkan dengan pemain-pemain yang lain. 


\section{KESIMPULAN}

Dalam pemainan dan olahraga bola voli dapat membuat tubuh menjadi sehat karena mengeluarkan keringat dari tubuh. Bola voli juga dapat mehilangkan atau menghidari kejenuhan siswa / siswi dalam mempelajari teknik dasar pemain bola voli. Karena, pemainan dan olahraga bola voli mempunyai peraturan yang dimodifikasi yang membuat siswa / siswi dapat mehilangkan atau menghindari kejenuhan ketika belajar atau memainkan permainan atau olahraga bola voli ini.

Dalam rangkah memainkan permainan bola voli ini, permainan ini dapat dilakukan dengan cara membuat lapangan kecil dengan teknik passing bawah dan cara servis tangan bawah, dan hendaklah dalam permainan atau olahraga bola voli ini ditekankan penggunaan teknik yang benar dan terarah sehingga bisa lebih meningkatkan penguasaan teknik nya dalam permainan bola voli itu sendiri. Dan bagi orang yang kelebih lemak, mungkin dengan memainkan permainan bola voli ini bisa membakar lemak karena hasil pembakaran yaitu dengan mengeluarkan keringat bias sedikit demi sedikit membuat kita mempunyai tubuh yang ideal. 


\section{DAFTAR PUSTAKA}

http://inforingankita.blogspot.com/2012/03/makalah-lempar-lembing-olah-raga.html http://www.referensimakalah.com/2013/04/sejarah-olahraga-lempar-lembing.html http://musranaceh.blogspot.com/2013/01/normal-0-false-false-false-in-x-none-x.html https://anfazeps.wordpress.com/2012/08/05/sarana-dalam-permainan-bola-voli/ http://sport.detik.com/read/2014/08/27/013912/2673574/82/tim-putra-dan-putri-indonesia-jadirunner-up-kejuaraan-voli-sekolah-se-asia 